Article - Human \& Animal Health

\title{
International and Brazilian Versions of WHOQOL-DIS: (in)adequacy to its Underpinnings
}

\author{
José Roberto Herrera Cantorani ${ }^{{ }^{*}}$ \\ https://orcid.org/0000-0003-1792-0383 \\ Bruno Pedroso 2 \\ https://orcid.org/0000-0002-7905-2393 \\ Leandro Martinez Vargas ${ }^{2}$ \\ https://orcid.org/0000-0001-7324-4450 \\ Claudia Tania Picinin ${ }^{3}$ \\ https://orcid.org/0000-0003-4844-3516 \\ Luiz Alberto Pilatti ${ }^{3}$ \\ https://orcid.org/0000-0003-2679-9191
}

\section{Gustavo Luis Gutierrez ${ }^{4}$}

https://orcid.org/0000-0002-2383-8696

\begin{abstract}
${ }^{1}$ Federal Institute of São Paulo, Registro, São Paulo, Brazil; 2State University of Ponta Grossa, Ponta Grossa, Paraná, Brazil; ${ }^{3}$ Federal University of Technology - Paraná, Ponta Grossa, Paraná, Brazil; ${ }^{4}$ State University of Campinas, Campinas, São Paulo, Brazil
\end{abstract}

Received: 2018.11.28; Accepted: 2019.09.03.

*Correspondence: cantorani@yahoo.com.br; Tel.: +55-43-996501903 (J.R.H.C.)

\section{HIGHLIGHTS}

- International version of WHOQOL-DIS presents limitations.

- Brazilian version of the WHOQOL-DIS differs from international version.

- New questions of Brazilian version do not compose the calculation of score.

- Limitations of original version remain in Brazilian version.

Abstract: The present article aims to analyze the WHOQOL-DIS (World Health Organization Quality of Life - Disabilities) structure to verify this instrument's adequacy to the theoretical principles underlying its construction. The methodology consists in an analysis of the WHOQOL-DIS underlying theory, prompting questions about the adequacies of this theoretical model. The procedure is complemented by a syntax analysis in order to verify the relevant questions for the score calculation. The obtained results show that the subjects "participation" and "autonomy" are not objectively present in the international version, 
although they are considered in the theories as justifying elements for the instrument's creation. In the Brazilian version, there are questions addressed to the themes. However, these questions are also not factored into the score calculation. In conclusion, the presence of autonomy and participation in the Brazilian version of WHOQOL-DIS represents a proximity with the theoretical assumptions underlying its creation. However, because they do not compose the score calculation, this adequacy is still limited.

Keywords: quality of life; disabled persons; disability evaluation.

\section{INTRODUCTION}

The 1970s has brought significant advances for the rights and equal conditions for persons with disabilities, and it has also enhanced the conceptual evolution of the debate on disability, especially those promoted by The Union of the Physically Impaired Against Segregation (UPIAS) [1-3], constituting a form of cornerstone for the development of studies directed to this population. Among these studies are those for the assessment of quality of life developed by the World Health Organization (WHO) [4-6].

Debates encouraged by UPIAS have rendered another perspective of disability, which highlights the role of accessibility for its (in)effectiveness. Such perspective redefines the context of deficiency through the social model of disability, which is supported by welfare policies and social justice, reinforcing the fact that the traditional explanation for disability the biomedical model - does not suffice. The theoretical basis of this model sets out that disability does not arise solely from the individual and physical limitations, but rather from the interaction between the physical characteristics of the individuals and social conditions in which they live. That is, the combination of the limitations imposed by body - the result of some kind of loss or reduction of functionality - and the social organization, which is inconsiderate about body diversity $[1,2,7]$.

In order to highlight this context, the UPIAS describes, based on the Persons with disabilities's perspective/sensation, two terms: impairment as the "partial or total absence of a limb, organ or existence of a defective body mechanism"; and disability as the "disadvantage or activity restriction caused by contemporary social organization, which does not acknowledge, or barely, those who have physical limitations and, therefore, excludes the participation of the main activities of social life" [1].

This change in terms of the perception of disability and, consequently, in the conceptual model of disability led to a social and theoretical restructuring of its foundation. Among the restructuring measures is the elaboration and, subsequently, the reformulation of the International Classification of Impairments, Disabilities, and Handicaps: a manual of classification relating to the consequences of disease (ICIDH).

The ICIDH was developed by the WHO in 1976 and was designed to be a disability classification manual. It has brought significant contributions, but it has also been criticized for reinforcing the biomedical approach to understand disability, based upon the idea that the inability / disability is the direct result of the disease or disorder [8-10]. Due to this fact, the WHO reviewed in 2001 the ICIDH - now called "preliminary" - and from that review, they elaborated a new document, the International Classification of Functioning, Disability and Health (ICF), which is also described by the WHO as International Classification of Functioning, Disability and Health (ICIDH2). With aid of the ICF, the WHO seeks to adapt effectively to the perspective of the social model of disability $[7,11]$. The ICF adopts the concept based on the biopsychosocial model, an overview of the medical model and the social approaches to disability $[8,10,12]$.

After the conceptual adequacy of the $\mathrm{ICIDH}$, the WHO also realized the need to adequate Persons with disabilities-oriented quality of life assessment tools. Given this necessity, the challenge to develop a guided instrument within such theoretical parameters $[4,5]$ has to be faced. On the basis of this theoretical scope, the WHOQOL- DIS emerges as a quality of life assessment tool directly targeted to Persons with disabilities.

As a result of this process, three versions of the WHOQOL-DIS were developed: one for people with physical disabilities (WHOQOL-DIS-PD), one for people with intellectual 
disabilities (WHOQOL-DIS-ID) and another for careers of people with intellectual disabilities (WHOQOL-DIS-ID Proxy).

Meanwhile, so that the instrument may be applied in Brazil, researchers developed a Brazilian version of WHOQOL-DIS. This version features five additional questions, bracketed in a module called the Local Module, which is present in the three versions of the instrument: WHOQOL-DIS-PD, WHOQOL-DIS-ID and WHOQOL-DIS-ID Proxy [13].

In a lift realized in Scielo, ScienceDirect, Scopus and Web of Science databases we found 22 articles portraying studies related to WHOQOL-DIS. Among these, however, only the Lucas-Carrasco and Gomez-Benito's [14], Lucas-Carrasco et al. [15] and Jovanović et al. [16] studies portrayed the instrument application, being the other ones related to the development, translation and its psychometric properties testing process.

This study aims to analyze the construction and structure of WHOQOL- DIS in terms of this instrument's approach to the biopsychosocial model of disability. In order to conduct this study, issues that constitute the instrument shall be taken into consideration, as well as the elements that make up the Local Module of the Brazilian version, and also the structured syntaxes to calculate the three versions of this instrument.

\section{MATERIAL AND METHODS}

Firstly, for the development of the present analysis, documents that provide the theoretical guidelines to support the construction and structuring of the WHOQOL-DIS by the WHO were analyzed. In this stage, a set of documents consisting of three texts of UPIAS (Fundamental Principles of Disability, Discuss Fundamental Principles of Disability and Disability Challenge) and by ICIDH2 was interpreted. This interpretation was substantiated by an analysis of the papers published by the DIS-QOL Group, who developed the WHOQOL-DIS instrument, with which the frequency of appearance of terms relevant to the object under study was collected. Qualitatively, the equivalence of the terms was verified, as well as their association with a theme identified as central [17].

The documentary procedure followed the criteria and care appointed by Smit [18]: "gather and organize to find". In general, the task is to regard the thematic processing of information, which in turn is related to the analysis, detailing and organization of the documents' content, as well as their associations with the supporting theories.

The analysis of the documents' content identified two relevant matters for the life and the quality of life of Persons with disabilities: "participation" and "autonomy".

This led us to the analysis of the questions of the WHOQOL-DIS and the relevant syntaxes for the calculation of the versions of this instrument in the Statistical Package for Social Sciences (SPSS). Consequently, this analysis was also directed to the syntax of the Brazilian versions of the aforementioned instrument. By means of this analysis, the goal this stage was to verify the procedure used to calculate the scores of the facets and the instrument fields, especially in order to comprehend the relevance of WHOQOL- DIS questions in this evaluation process of quality of life assessment of Persons with disabilities.

In terms of the syntaxes, they were transcribed, interpreted and analyzed with focus on the criteria adopted for the calculation of scores of facets and areas of the instrument.

\section{RESULTS}

\section{Theoretical guidelines supporting WHOQOL-DIS' construction}

Based on the analysis of the investigated document, two central themes could be identified: "participation" and "autonomy". These two terms are widely reoccurring in the three texts of the UPIAS and the ICIDH2, which are considered as the theoretical support for the development of the WHOQOL-DIS.

Table 1 shows the categories associated with the theme "Active Participation" and their respective equivalent terms, identified in the table as components. The data in this table was gathered from the content analysis of the three UPIAS' texts.

Table 1. Categories associated with the active participation in the texts of UPIAS 
Cantorani, J.R.H.; et al.

\begin{tabular}{|c|c|c|c|c|c|c|c|c|}
\hline \multirow[t]{2}{*}{ Categories } & \multirow[t]{2}{*}{ Components } & \multicolumn{3}{|c|}{ Frequency } & \multirow[t]{2}{*}{ Total } & \multirow[t]{2}{*}{$\%$} & \multicolumn{2}{|c|}{ Total } \\
\hline & & $\mathrm{T} 1$ & $\mathrm{~T} 2$ & T3 & & & $\mathrm{FT}$ & $\%$ \\
\hline \multirow[t]{7}{*}{ Participation } & Participation & 16 & 13 & 38 & 67 & 70.5 & 95 & 28.8 \\
\hline & Participate & 2 & 1 & 12 & 15 & 15.8 & & \\
\hline & Participating & 1 & 1 & 2 & 4 & 4.2 & & \\
\hline & Participant & 1 & 1 & 2 & 4 & 4.2 & & \\
\hline & Participants & - & - & 3 & 3 & 3.2 & & \\
\hline & Participative & - & - & 1 & 1 & 1.05 & & \\
\hline & Participated & - & - & 1 & 1 & 1.05 & & \\
\hline \multirow[t]{7}{*}{ Integration } & Integration & 8 & 8 & 16 & 32 & 43.2 & 74 & 22.4 \\
\hline & Integrated & 7 & 6 & 14 & 27 & 36.5 & & \\
\hline & Integrate & 2 & 2 & 2 & 6 & 8.1 & & \\
\hline & Integrative & 2 & 2 & - & 4 & 5.4 & & \\
\hline & Integrity & - & - & 2 & 2 & 2.7 & & \\
\hline & Integral & 1 & 1 & - & 2 & 2.7 & & \\
\hline & Integrating & - & - & 1 & 1 & 1.4 & & \\
\hline \multirow[t]{4}{*}{ Inclusion } & Include & 4 & 2 & 5 & 11 & 39.3 & 28 & 8.4 \\
\hline & Includes & 3 & 2 & 3 & 8 & 28.6 & & \\
\hline & Including & 4 & 3 & - & 7 & 25.0 & & \\
\hline & Included & - & 1 & 1 & 2 & 7.1 & & \\
\hline \multirow[t]{3}{*}{ Access } & Accessible & 4 & 4 & 1 & 9 & 64.3 & 14 & 4.2 \\
\hline & Accessibility & 2 & 2 & 0 & 4 & 28.6 & & \\
\hline & Access & - & - & 1 & 1 & 7.1 & & \\
\hline \multirow[t]{7}{*}{ Segregation } & Segregation & 9 & 1 & 19 & 29 & 42.6 & 68 & 20.5 \\
\hline & Segregated & - & - & 28 & 28 & 41.2 & & \\
\hline & Segregate & 1 & 1 & 2 & 4 & 5.9 & & \\
\hline & Segregationist & 1 & 1 & 1 & 3 & 4.4 & & \\
\hline & Segregationists & - & - & 2 & 2 & 2.9 & & \\
\hline & Segregates & - & - & 1 & 1 & 1.5 & & \\
\hline & Segregating & - & - & 1 & 1 & 1.5 & & \\
\hline \multirow[t]{4}{*}{ Exclusion } & Exclusion & 9 & 8 & 5 & 22 & 42.3 & 52 & 15.7 \\
\hline & Excluded & 6 & 4 & 1 & 11 & 21.2 & & \\
\hline & Exclude & 3 & 3 & 4 & 10 & 19.2 & & \\
\hline & Excludes & 3 & 4 & 2 & 9 & 17.3 & & \\
\hline TOTAL & All words & & & & & & 331 & 100 \\
\hline
\end{tabular}

Table 2 shows the categories associated with the theme "Autonomy" and their equivalent terms, identified in the table as components. The data in this table was gathered from the content analysis of the three UPIAS' texts. 
Table 2. Categories associated with the autonomy presents in the texts of UPIAS

\begin{tabular}{|c|c|c|c|c|c|c|c|c|}
\hline \multirow[t]{2}{*}{ Categories } & \multirow[t]{2}{*}{ Components } & \multicolumn{3}{|c|}{ Frequency } & \multirow[t]{2}{*}{ Total } & \multirow[t]{2}{*}{$\%$} & \multicolumn{2}{|c|}{ Total } \\
\hline & & $\mathrm{T} 1$ & $\mathrm{~T} 2$ & T3 & & & $\mathrm{FT}$ & $\%$ \\
\hline \multirow[t]{5}{*}{ Activity } & Active & 15 & 11 & 32 & 58 & 50.9 & 114 & 45.2 \\
\hline & Activities & 12 & 6 & 10 & 28 & 24.5 & & \\
\hline & Activity & 3 & 3 & 11 & 17 & 14.9 & & \\
\hline & Actively & 2 & 2 & 6 & 10 & 8.8 & & \\
\hline & Inactive & - & - & 1 & 1 & 0.9 & & \\
\hline \multirow[t]{5}{*}{ Control } & Control & 16 & 5 & 17 & 38 & 76.0 & 50 & 19.8 \\
\hline & Controlling & 1 & 1 & 3 & 5 & 10.0 & & \\
\hline & Controlled & 1 & 1 & 2 & 4 & 8.0 & & \\
\hline & Controllers & 1 & 1 & - & 2 & 4.0 & & \\
\hline & Controls & - & - & 1 & 1 & 2.0 & & \\
\hline \multirow[t]{5}{*}{ Independence } & Independence & 4 & 4 & 4 & 12 & 28.60 & 42 & 16.7 \\
\hline & Dependence & 4 & 4 & 4 & 12 & 28.60 & & \\
\hline & Independent & 2 & 1 & 4 & 7 & 16.65 & & \\
\hline & Dependent & 3 & 2 & 2 & 7 & 16.65 & & \\
\hline & Independently & - & - & 4 & 4 & 9.50 & & \\
\hline \multirow[t]{2}{*}{ Capacity } & Capacity & 5 & 3 & 2 & 10 & 50.0 & 20 & 7.9 \\
\hline & Incapacity & 5 & 5 & - & 10 & 50.0 & & \\
\hline \multirow[t]{2}{*}{ Emancipation } & Emancipation & 3 & 2 & 6 & 11 & 84.6 & 13 & 5.2 \\
\hline & Emancipating & 1 & 1 & - & 2 & 15.4 & & \\
\hline \multirow[t]{3}{*}{ Mobility } & Mobility & 5 & 1 & 4 & 10 & 76.9 & 13 & 5.2 \\
\hline & Immobility & 1 & 1 & - & 2 & 15.4 & & \\
\hline & Immobile & - & - & 1 & 1 & 7.7 & & \\
\hline TOTAL & All words & & & & & & 252 & 100 \\
\hline & $\begin{array}{r}\text { Sour } \\
\text { T1 Text Disc } \\
\text { T2 Text }\end{array}$ & $\begin{array}{l}\text { dapte } \\
\text { unda } \\
\text { amen } \\
\text { xt Di }\end{array}$ & $\begin{array}{l}\text { rom } \\
\text { ntal } \\
\text { Prin }\end{array}$ & $\begin{array}{l}\text { PIAS } \\
\text { pincip } \\
\text { ples }\end{array}$ & $\begin{array}{l}\text { xts } \\
\text { of Disab } \\
\text { sability }\end{array}$ & & & \\
\hline
\end{tabular}


Table 3 presents the categories associated with the themes "Participation" and "autonomy" and their equivalent terms. These data was extracted from the content analysis performed on ICIDH2.

Table 3. Categories associated with the autonomy and participation presents in the ICIDH2

\begin{tabular}{|c|c|c|c|c|c|}
\hline \multirow[t]{2}{*}{ Categories } & \multirow[t]{2}{*}{ Components } & \multirow[t]{2}{*}{ Frequency } & \multirow[t]{2}{*}{$\%$} & \multicolumn{2}{|c|}{ Total } \\
\hline & & & & FT & $\%$ \\
\hline Impairment & Impairment & 229 & 100 & 229 & 21.7 \\
\hline \multirow[t]{2}{*}{ Activity } & Activities & 102 & 71.8 & 142 & 13.5 \\
\hline & Activity & 40 & 28.2 & & \\
\hline Environment & Factor Environmental & 123 & 100 & 123 & 11.7 \\
\hline \multirow[t]{5}{*}{ Participation } & Participation & 111 & 94.9 & 117 & 11.1 \\
\hline & Participanting & 2 & 1.7 & & \\
\hline & Participants & 2 & 1.7 & & \\
\hline & Participant & 1 & 0.85 & & \\
\hline & Paticipate & 1 & 0.85 & & \\
\hline Performance & Performance & 104 & 100 & 104 & 9.9 \\
\hline \multirow[t]{2}{*}{ Capacity } & Capacity & 92 & 97.9 & 94 & 8.9 \\
\hline & Capacities & 2 & 2.1 & & \\
\hline Task & Tasks & 78 & 100 & 78 & 7.4 \\
\hline \multirow[t]{4}{*}{ Interaction } & Interactions & 48 & 68.6 & 70 & 6.6 \\
\hline & Interaction & 13 & 18.6 & & \\
\hline & Interact & 5 & 7.1 & & \\
\hline & Interacting & 4 & 5.7 & & \\
\hline \multirow[t]{2}{*}{ Limitation } & Limitations & 28 & 53.8 & 52 & 4.9 \\
\hline & Limitation & 24 & 46.2 & & \\
\hline Mobility & Mobility & 45 & 100 & 45 & 4.3 \\
\hline TOTAL & All words & & & 1054 & 100 \\
\hline
\end{tabular}

Source: Adapted from ICIDH2

FT Frequency with which all the components of appear each category

\section{Analysis of the underlying structure during the development and construction of WHOQOL-DIS}

In order to ensure the transcultural condition, the WHOQOL-DIS project was developed in research centers from different parts of the world (Edinburgh, United Kingdom; Barcelona, Spain; Paris, France; Prague, Czech Republic; Tromso, Norway; Izmir, Turkey; Vilnius, Lithuania; Sicily, Italy; Hamburg, Germany; Tilburg, Netherlands; Guangzhou, China; Porto Alegre, Brazil; Montevideo, Uruguay; Auckland, New Zealand; Budapest, Hungary). The project was conducted by the University of Edinburgh, and each center performed the same essential components of the project at the same time $[4,19,20]$. The DIS-QOL project aimed to develop an instrument that would allow an assessment of the quality of life of people with physical disabilities, as well as of those intellectual disabilities [4,5,21,22].

The end result of the work provided the way to elaborate three versions: one for people with physical disabilities (WHOQOL-DIS-PD); one for people with intellectual disabilities (WHOQOL-DIS-ID); and another for those responsible and/or caregivers of people with intellectual disabilities (WHOQOL-DIS-ID Proxy), for cases in which the Persons with disabilities have no condition to respond [5].

The domain structure, facets, and content of representative questions of each facet is the same for all three versions. These versions are characterized by the condition of 
additional module to the WHOQOL-bref. The structure of these modules covers 13 facets: one that assesses, in general, the impact of disabilities on the population of quality of life (impact of disability), and other 12 subdivided into three domains (Domain I - Discrimination: discrimination, advocacy, future prospects; Domain II - Autonomy: control, choice, autonomy; Domain III - Inclusion: communication ability, social acceptance, respect, social network and interaction, social inclusion and contribution, personal potential).

The difference between the three instruments occurs due to small adjustments made in WHOQOL-DIS-ID and WHOQOL-DIS-ID Proxy. These adjustments bore in mind the adaptation of the instruments to people with intellectual disabilities and to their caregivers.

The WHOQOL-DIS-PD instrument, directed to people with physical disabilities, follows the same structure of responses observed in the original assessment instruments of the WHOQOL, for which a Likert scale of 5 points is used. The WHOQOL-bref also remains unchanged for the application to this group.

As for the WHOQOL-DIS-ID instrument for people with intellectual disabilities, the Likert scale was changed from 5 to 3 points $[4,5,22,23]$. The research that oriented the DIS-QOL Group pointed out (21) the fact that the Likert scale with five response points was not suitable for intellectual disabilities (19). For example, studies have shown that people with low literacy level have difficulty understanding the five-points answer of the Likert scale [25]; people with intellectual disabilities are not able to grasp effectively the five-point scale [26]; and that people with low educational level do not have a valid discernment to answer the scale of five points of the WHOQOL-bref [27].

Thus, based on the analysis of this data set and also from the pilot study of WHOQOL-DIS, it was concluded that a response structure with a 3 - point scale is the most appropriate for research with people with intellectual disabilities [4,22]. For the same reason, the WHOQOL-bref aimed at this group has also been changed from 5 to 3 points in their response scale. However, the representative questions of broad fields of both the WHOQOL-bref and the WHOQOL-DIS-ID remained on five-point scales [5].

The Likert scale for the WHOQOL-DIS-ID Proxy instrument, which considers those responsible and/or caregivers of people with intellectual disabilities, was unchanged, remaining with 5 points. The questions were posed in order to refer to the individuals with disabilities. The same happened applies in the WHOQOL-bref. The content of the questions of both instruments remains the same $[5,23]$.

For the application to a group of people with intellectual disabilities and the group of caregivers, the WHOQOL-bref's structure was altered, but its content was preserved. The questions of this instrument were simplified, and some examples were added to facilitate the comprehension of both groups. The new versions of the WHOQOL-bref were named, WHOQOL-bref-ID and WHOQOL-bref-ID Proxy, respectively [5].

The scales of WHOQOL- DIS answers also received illustrations. The illustrations are facial expressions that represent satisfaction and are present in three modules [4]. In the WHOQOL-DIS-PD instrument, facial expressions are present only in the additional module. Therefore, they are not part of the WHOQOL-bref instrument. In the instruments WHOQOLDIS-ID and WHOQOL-DIS-ID Proxy, facial expressions are present both in the module, as well as in the WHOQOL-bref.

Representative questions of each WHOQOL-DIS facet are arranged in Table 4. Similarly to the WHOQOL-bref, this module consists of a corresponding question for each facet. However, there is a difference in relation to the facet's representation of the general aspect: whereas there are two questions in the WHOQOL-bref,, the WHOQOL-DIS module poses only one question. 
Table 4. Facets and questions of WHOQOL-DIS

\begin{tabular}{|c|c|c|}
\hline Facets & $\mathrm{N}$ & Questions \\
\hline General & 27 & $\begin{array}{l}\text { Does your disability have a negative (bad) effect on your day-to-day } \\
\text { life? }\end{array}$ \\
\hline Discrimination & 28 & Do you feel that some people treat you unfairly? \\
\hline Advocacy & 29 & $\begin{array}{l}\text { Do you need someone to stand up for you when you have } \\
\text { problems? }\end{array}$ \\
\hline Future prospects & 30 & $\begin{array}{l}\text { Do you worry about what might happen to you in the future? } \\
\text { For example, thinking about not being able to look after yourself, or } \\
\text { being a burden to others in the future. }\end{array}$ \\
\hline Control & 31 & $\begin{array}{l}\text { Do you feel in control of your life? } \\
\text { For example, do you feel in charge of your life? }\end{array}$ \\
\hline Choice & 32 & $\begin{array}{l}\text { Do you make your own choices about your day-to-day life? } \\
\text { For example, where to go, what to do, what to eat. }\end{array}$ \\
\hline Autonomy & 33 & $\begin{array}{l}\text { Do you get to make the big decisions in your life? } \\
\text { For example, deciding where to live, or who to live with, how to } \\
\text { spend your money. }\end{array}$ \\
\hline $\begin{array}{l}\text { Communication } \\
\text { ability }\end{array}$ & 34 & $\begin{array}{l}\text { Are you satisfied with your ability to communicate with other } \\
\text { people? } \\
\text { For example, how you say things or get your point across, the way } \\
\text { you understand others, by words or signs. }\end{array}$ \\
\hline Social acceptance & 35 & Do you feel that other people accept you? \\
\hline Respect & 36 & Do you feel that other people respect you? \\
\hline Social network and & & $\begin{array}{l}\text { For example, do you feel that others value you as a person and } \\
\text { listen to what you have to say? }\end{array}$ \\
\hline interaction & 37 & $\begin{array}{l}\text { Are you satisfied with your chances to be involved in social } \\
\text { activities? } \\
\text { For example, meeting friends, going out for a meal, going to a party } \\
\text { etc. }\end{array}$ \\
\hline $\begin{array}{l}\text { Social inclusion and } \\
\text { contribution }\end{array}$ & 38 & $\begin{array}{l}\text { Are you satisfied with your chances to be involved in local activities? } \\
\text { For example, being part of what is happening in your local area or } \\
\text { neighborhood. } \\
\text { Do you feel that your dreams, hopes and wishes will happen? }\end{array}$ \\
\hline Personal potential & 39 & $\begin{array}{l}\text { For example, do you feel you will get the chance to do the things you } \\
\text { want, or get the things you wish for, in your life? }\end{array}$ \\
\hline
\end{tabular}

Source: Adapted from WHOQOL-Disabilities module manual in WHO [5] and Power and Green [4]

\section{Analysis of the Brazilian WHOQOL-DIS structure}

The structure presented in the "International Version" of the WHOQOL-DIS is basically the same as in the "Brazilian Version". However, the latter is increased by a set of questions that are termed "local module" (table 5).

This local module in the Brazilian Field Test Version consists of "five local items 'environmental adaptations to constraints', 'physical barriers', 'employment opportunities', 'learning opportunities' and 'food'" [13]. According to the group responsible for the instrument's development in Brazil, the inclusion of this local module this site module is justified by the fact that it depicts more accurately the reality of PdW's lives. 
However, the item "physical barriers (question 44)" (table 5) does not appear in the local module of the Brazilian version of the validation article published by the group responsible for the instrument's development in Brazil [13]. In this case, the local module consists of only four items.

Table 5. Questions of the Brazilian version of WHOQOL-DIS

\begin{tabular}{ll}
\hline $\mathrm{N}$ & \multicolumn{1}{c}{ Questions } \\
\hline 40 & Are you satisfied with the opportunities you have to work? \\
& For example, with the job offers you receive. \\
41 & Are you satisfied with the adaptations of your environment to your limitation? \\
& For example, access ramps, adapted restrooms, elevators, in the case of moving \\
& difficulty; signaling in the streets, in the case of visual impairment; sign language \\
& interpreters, in the case of hearing impairment. \\
& Are you satisfied with the opportunities you have to study? \\
& For example, if you want a school or university to accept you as a student. \\
& Are you satisfied with your nutrition? \\
& For example, with the amount and quality of the food you eat. \\
& Do physical barriers in its environment affect its daily life? \\
& For example, steps, stairs and slopes, in the case of difficulty of moving; holes in \\
streets, in the case of visual impairment; lack of people who speak LIBRAS, in the \\
case of hearing loss.
\end{tabular}

But it is worth emphasizing that the item "physical barriers (question 44)" is present in the Brazilian Field Test Version used in doctoral theses associated with the group responsible for developing the instrument in Brazil $[28,29]$. The absence of this item in that article can be justified by an error in the construction of the table that contains the WHOQOL-DIS module questions, due to the fact that the item is mentioned in the publication [28].

The analyses carried out by the group responsible for developing the instrument were based on classical psychometric methods and were conducted independently for the two study samples: PD and ID. In order to evaluate the normality of distribution, the Shapiro-Wilk test and Kolmogorov-Smirnov test were employed. Both the relationship between the variables and the WHOQOL-DIS domains, and the evidence of criterion validity were analyzed using the $\mathrm{t}$ test for independent samples, if normally distributed; or the Mann-Whitney $U$ test, otherwise. For the two subsamples, an exploratory factor analysis was performed [13]. The Cronbach's alpha was calculated for the reliability proof of the instrument scales and subscales. In the subsample ID, the test-retest reliability was analyzed by means of the intraclass correlation coefficient (ICC, the average measures of two random ways) and the t test for paired samples (domain averages) [13]. The results turned out to be satisfactory.

\section{Analysis of syntaxes for calculating the scores of WHOQOL-DIS}

The written transcript of WHOQOL- DIS syntax is presented as follows:

- All 12 questions must be filled out with values between 1 and 3 (the ID version) or between 1 and 5 (the PD and Proxy versions);

- All questions whose range of responses is reversed are inverted;

- The score of the disabilities module (WHOQOL-DIS) is calculated through the average number of the 12 specific questions that constitute the WHOQOL-DIS, which will only be calculated if the number of unanswered or incorrectly answered specific questions is 
equal or greater than three. The result is multiplied by 12 and is depicted in a scale from 12 to 36 in the ID version, or in a scale from 12 to 60 in the versions DP and proxy;

- $\quad$ The WHOQOL-DIS score is converted to a scale from 0 to 100.

Analogously to the WHOQOL-OLD, the WHOQOL-DIS is an additional module which is to be employed in conjunction with the general assessment modules WHOQOL-100 and WHOQOL-bref. Differently from WHOQOL instruments, WHOQOL-DIS is the first to present different versions. It is also the first to use a range of responses that differ from other instruments. The general questions of the WHOQOL-bref-ID (1G and $2 \mathrm{G}$ ) and the general question of the WHOQOL-DIS-ID (27G) have a range of responses containing five items, such as in other WHOQOL instruments, while other questions have a scale responses composed of three items.

\section{Analysis of syntaxes for calculating the score of Brazilian versions of WHOQOL-DIS}

Among the additional questions of the local module of the Brazilian version, the question relating to environmental physical barriers is reversed.

In the context of the ongoing analysis, it is relevant to point out that local module questions of the Brazilian version of WHOQOL-DIS are not factored in the score. These questions are posed solely for a better understanding of the target audience [13].

\section{DISCUSSION}

The topics of "active participation" (table 1) and "autonomy" (table 2) are widely discussed in the texts of UPIAS [1-3,30]. Active participation concerns the full social participation of Persons with disabilities. This involves the participation in personal development activities, such as decisions about what concerns you, study and work activities for self-sustenance. The theme of autonomy, in turn, is linked to independence and concerns the structuring of an environment that enables such a condition. This structuring encompasses adjustments to minimize the barriers, both at residential level, as well as everything related to social life.

The ICIDH2 also presented the categories that justify the selection of the same thematic axes: participation and autonomy (table 3). The focus of ICIDH2, however, is on the functionality and restrictions on the body [11]. This instrument has two major evaluation focuses: functionality and disability components, represented by the body's functionality and the participation and development of activities; and contextual factors, represented by environmental and personal factors. These ICIDH2 evaluation focuses underline the relevance given by WHO to the themes autonomy and participation. Several studies have highlighted the importance of these themes to the Persons with disabilities [31-34].

The DIS-QOL Group estimated that the WHOQOL-DIS would have significant impact due to the psychometric advantages of transcultural assessment and the wide possibility of using this instrument. The aforementioned Group's perspective is that the instrument can be used for the evaluation of different approaches to assess the welfare of Persons with disabilities, taking into consideration social and health questions [19].

The additional WHOQOL-DIS module, in fact, added specificity to the assessment context of quality of life of Persons with disabilities. The specific approach, as a result of the valuation of the impact of disability, discrimination, autonomy and inclusion in the quality of life of these people gives legitimacy to the expectation of the DIS-QOL Group. The psychometric properties of the instrument also offer evidence of its validity and reliability. These tests are represented by the construct validity, conducted through factor analysis, the internal consistency (Cronbach's alpha), and hypothesis testing (test group); the criterion validity, performed by concurrent and discriminant validity; and test-retest reliability [13].

However, compared to analysis in focus, it must be stressed that the attention to participation and autonomy - topics of great relevance to the context, as noted - was not taken at the level that is presented in the theoretical underlying assumptions that justify the creation of an instrument, such as the case of the WHOQOL-DIS. 
On the topic of participation, the questions 34 to 39 give structure to the theme. These six questions, each one with its specificity, offer the evaluation condition of the condition of the sense of participation on the part of Persons with disabilities.

Regarding the autonomy, the questions 31, 32 and 33 represent this facet. However, they question the individuals on their autonomy in major decisions about their life, for example, if they decide where to live, how to feed or how they spend their money. The addressed autonomy, in such perspective, do not infer autonomy as the condition to come and go, or to perform daily life activities, which, in a way, is related to accessibility.

Questions 41 and 44 - only present in the Brazilian version (table 5) - offer direct relation to autonomy concerning accessibility. Notwithstanding, this sphere represents significant areas for the quality of life of Persons with disabilities [4,20,21,35]. In a way, this autonomy is also related to a condition of participation, because without the condition for access, the participation is compromised.

This context allows us to question about the fact that the two questions that show relevance to the adequacy of the instrument to ICIDH2 are not part of the international version. These questions give particular attention to what is advocated in the social model of disability, meaning that the body disabilities, or functional level, occurs due to the influence of the environment in which the person is inserted [1,2,8-10). It is worth mentioning that this deficiency interpretation influenced the WHO to elaborate the ICIDH2 [4,5,20].

Disability is characterized as an interaction between the intrinsic characteristics of the individual and the physical and social environment [11,12]. Thus, the two questions - in direct reference to autonomy and accessibility - depict the perspective of Persons with disabilities on the influence of the environment on their quality of life. It is worth mentioning that well-being is perceived individually by the subjects, and can, consequently, best be judged by them [36]. Therefore, quality of life must be considered from the individual's perspective; and from this this factor that the evaluation ought to be conducted [37].

Nevertheless, it should be noted that, although these two questions are part of the Brazilian version of WHOQOL-DIS, they are not factored into the score calculation, as well as other questions of the aforementioned module. The local module questions serve solely to better understand the target audience. Consequently, even in the Brazilian version, the importance of autonomy and participation is neglected in the evaluation process.

The general question concerning the impact of disability of the present instruments also did not use it as a basis to calculate any scores. This is due to the imbalance caused by this question in the psychometric properties of the WHOQOL-DIS module. Although it not used for calculation of scores, it was still kept in the instrument.

In a general context, even if specific areas for additional module WHOQOL-DIS have been defined, the SPSS syntax proposed for the different versions of the WHOQOL-DIS does not consider the calculation of such domain scores.

Given the change in the answer scale of the WHOQOL-bref version during the application of WHOQOL-DIS for people with intellectual disabilities - WHOQOL-bref-ID -, a syntax corresponding such instrument should also have been made available, which in fact did not occur.

\section{CONCLUSION}

Due to the fact that international version of the WHOQOL-DIS tool does not address the questions 41 and 44,whose structures are directly related to the theoretical concept that led the WHO to its construction, and, hence results in a lesser capacity of this instrument to adapt to the ICIDH2 and the psychosocial model deficiency.

These questions imply the environment's influence on the daily life of Persons with disabilities, and consequently concern the factors autonomy and accessibility. Failing to include these issues neglect the fact that accessibility and autonomy are conceptually related to the (in)existence of the disability. It is not without reason that the mention of these two components is significant both in the documents of UPIAS, as in those of ICIDH2. This set of facts leads to the understanding that these two would bring the instrument closer to the concept and the goal that spurred its creation. 
The presence of representative questions regarding autonomy, which were set in the condition of access, credits the structure of the Brazilian version of WHOQOL-DIS a more appropriate setting to the theoretical assumptions of its creation. However, the fact that these questions are not factored into the score calculation also bestows the Brazilian version a condition of unsuitability for the instrument's theoretical construction principles.

Although accessibility-related issues have been largely resolved in developed countries, a quality of life assessment instrument should not contain in its structure questions related solely to what is presumably flawed in the target audience's life. Thus, even though accessibility is not regarded as a problem in some countries, the existence of issues directed to this matter would allow an assessment of the relevance of such condition - in a positive manner - to the quality of life of this population.

\section{REFERENCES}

1. UPIAS. Fundamental principles of disability. Union of the Physically Impaired Against Segregation. London (UK): [publisher unknown]; 1975.

2. UPIAS. Disability Challenge. 1981.

3. UPIAS, Alliance TD. Discuss Fundamental Principles of Disabillity. Union of the Physically Impaired Against Segregation \& The Disability Alliance. London (UK): [publisher unknown]; 1997.

4. Power MJ, Green AM. Development of the WHOQOL disabilities module. Qual Life Res. 2010;19(4):571-84.

5. World Health Organization. WHOQOL-Disabilities module manual. Edinburgh (Scotland): University of Edinburgh, Section of Clinical and Health Psychology; 2011.

6. WHOQOL Group. Development of the WHOQOL: Rationale and Current Status. Int J Ment Health. 1994;23(3):24-56.

7. Medeiros M, Diniz D. Envelhecimento e deficiência. In: Os novos idosos brasileiros: muito além dos 60? Camarano AA, editor. Rio de Janeiro (Brazil): IPEA; 2004. p. 107-120.

8. Farias N, Buchalla CM. A classificação internacional de funcionalidade, incapacidade e saúde da organização mundial da saúde: conceitos, usos e perspectivas. Rev bras Epidemiol. 2005;8(2):187-93.

9. Zola IK. Toward the necessary universalizing of a disability policy. Milbank Q. 2005;83(4):1-27.

10. Mângia EF, Muramoto MT, Lancman S. Classificação Internacional de Funcionalidade e Incapacidade e Saúde (CIF): processo de elaboração e debate sobre a questão da incapacidade. Rev Ter Ocup Univ São Paulo. 2008;19(2):121-30.

11. World Health Organization. ICIDH-2: International classification of functioning, disability and health: final draft, full version. Geneva (Swiss): World Health Organization; 2001.

12. Bickenbach JE, Chatterji S, Badley EM, Üstün TB. Models of disablement, universalism and the international classification of impairments, disabilities and handicaps. Soc Sci Med. 1999;48(9):1173-87.

13. Bredemeier J, Wagner G, Agranonik M, Perez T, Fleck M. The World Health Organization Quality of Life instrument for people with intellectual and physical disabilities (WHOQOL-Dis): evidence of validity of the Brazilian version. BMC Public Health. 2014;14(1):538.

14. Lucas-Carrasco, R, Gomez-Benito, J. Quality of Life in persons with Physical Disabilities caused by neurodegenerative disorders: using the WHOQOL-DIS. Qual Life Res. 2010:19;58-8.

15. Lucas-Carrasco R, Pascual-Sedano B, Galán I, Kulisevsky J, Sastre-Garriga J, Gómez-Benito J. Using the WHOQOL-DIS to measure quality of life in persons with physical disabilities caused by neurodegenerative disorders. Neurodegener Dis. 2011;8(4):178-86.

16. Jovanović M, Lakićević M, Stevanović D, Milić-Rasić V, Slavnić S. Community-based study of health-related quality of life in spinal cord injury, muscular dystrophy, multiple sclerosis, and cerebral palsy. Disabil Rehabil. 2012;34(15):1284-90.

17. Bardin L. Análise de conteúdo. Lisboa (Portugal): Edições 70; 2002.

18. Smit JW. O que é documentação. São Paulo (Brazil): Brasiliense; 1986.

19. Power M. Final Report Summary - DIS-QOL (Quality of care and quality of life for people with intellectual and physical disabilities) [Internet]. Edinburgh: The University of Edinburgh; 2011 [cited ago 2012]. Available from: 
http://cordis.europa.eu/search/index.cfm?fuseaction=result.document\&RS_LANG=EN\&RS_RC $\mathrm{N}=12949207 \& \mathrm{q}=$.

20. Power MJ, Green AM, Group TW-D. The Attitudes to Disability Scale (ADS): development and psychometric properties. J Intellect Disabil Res. 2010;54(9):860-74.

21. Lucas-Carrasco R, Eser E, Hao Y, McPherson KM, Green A, Kullmann L. The Quality of Care and Support (QOCS) for people with disability scale: development and psychometric properties. Res Dev Disabil. 2011;32(3):1212-25.

22. Fang J, Fleck MP, Green A, McVilly K, Hao Y, Tan W, et al. The response scale for the intellectual disability module of the WHOQOL: 5-point or 3-point? J Intellect Disabil Res. 2011;55(6):537-49.

23. Schmidt S, Power M, Green A, Lucas-Carrasco R, Eser E, Dragomirecka E, et al. Self and proxy rating of quality of life in adults with intellectual disabilities: Results from the DISQOL study. Res Dev Disabil. 2010;31(5):1015-26.

24. Fleck MPA, SérgioLouzada, Xavier M, Eduardo Chachamovich, Vieira G, Santos L, et al. Aplicação da versão em português do instrumento abreviado de avaliação da qualidade de vida "WHOQOL-bref". Rev Saúde Pública. 2000;34(2):178-83.

25. Williams SA, Swanson MS. The effect of reading ability and response formats on patients' abilities to respond to a patient satisfaction scale. J Contin Educ Nurs. 2001;32(2):60-7.

26. Hartley SL, MacLean WE, Jr. A review of the reliability and validity of Likert-type scales for people with intellectual disability. J Intellect Disabil Res. 2006;50(11):813-27.

27. Chachamovich E, Fleck MP, Power M. Literacy affected ability to adequately discriminate among categories in multipoint Likert Scales. J Clin Epidemiol. 2009;62(1):37-46.

28. Bredemeier J. Qualidade de vida, qualidade de cuidado e atitudes frente a incapacidades em pessoas com incapacidades físicas e intelectuais. PhD in Medical Sciences, Porto Alegre, Universidade Federal do Rio Grande do Sul, 2013.

29. Chaveiro N. Qualidade de vida das pessoas surdas que se comunicam pela língua de sinais: construção da versão em libras dos instrumentos WHOQOL-BREF e WHOQOL-DIS. PhD in Health Sciences, Goiás, Universidade Federal de Goiás, 2011.

30. GMCDP. UPIAS (The Union of the Physically Impaired Against Segregation) Manchester: Greater Manchester Coalition of Disabled People; 2010 [cited 27 jul 2012]. Available from: http://gmcdp.com/our-history.

31. Perenboom RJM, Chorus AMJ. Measuring participation according to the International Classification of Functioning, Disability and Health (ICF). Disabil Rehabil. 2003;25(11-12):577-87.

32. Ueda S, Okawa Y. The subjective dimension of functioning and disability: what is it and what is it for? Disabil Rehabil. 2003;25(11-12):596-601.

33. O'Donovan M-A, Doyle A, Gallagher P. Barriers, activities and participation: Incorporating ICF into service planning datasets. Disabil Rehabil. 2009;25(31):2073-80.

34. Thyberg M, Arvidsson P, Thyberg I, Nordenfelt L. Simplified bipartite concepts of functioning and disability recommended for interdisciplinary use of the ICF. Disabil Rehabil. 2015;37(19):1783-92.

35. Andresen EM, Meyers AR. Health-related quality of life outcomes measures. Arch Phys Med Rehabil. 2000;81(Supplement 2): S30-S45.

36. Campbell A. Aspiration, Satisfaction, and Fulfillment. In: The human meaning of social change. Campbell A, Converse Pe, editors. New York (USA): Russell Sage Foundation; 1972. p. 441-66.

37. Campbell A, Converse PE. The human meaning of social change. New York (USA): Russell Sage Foundation; 1972. 